\title{
Lipoxygenases and their involvement in programmed cell death
}

\author{
M Maccarrone ${ }^{\star, 1}$, G Melino $^{1}$ and A Finazzi-Agrò ${ }^{*, 1}$ \\ ${ }^{1}$ Department of Experimental Medicine and Biochemical Sciences, University of \\ Rome Tor Vergata, I-00133 Rome, Italy \\ * Corresponding authors: Prof A Finazzi-Agrò or Dr M Maccarrone, Department \\ of Experimental Medicine and Biochemical Sciences, University of Rome Tor \\ Vergata, Via di Tor Vergata 135, I-00133 Rome, Italy. Tel: +39 0672596468 ; \\ Fax: +39 06 72596468; E-mail: Finazzi@uniroma2.it or \\ Maccarrone@med.uniroma2.it
}

Received 7.3.01; revised 9.5.01; accepted 10.5.01

Edited by $\mathrm{H}$ Ichijo

\begin{abstract}
Lipoxygenases are a family of enzymes which dioxygenate unsaturated fatty acids, thus initiating lipoperoxidation of membranes and the synthesis of signaling molecules. Consequently, they induce structural and metabolic changes in the cell in a number of pathophysiological conditions. Recently, a pro-apoptotic effect of lipoxygenase, and of the hydroperoxides produced thereof, has been reported in different cells and tissues, leading to cell death. Anti-apoptotic effects of lipoxygenases have also been reported; however, this has often been based on the use of enzyme inhibitors. Here we review the characteristics of the lipoxygenase family and its involvement in the initiation of oxidative stress-induced apoptosis. Finally, we discuss the role of lipoxygenase activation in apoptosis of animal and plant cells, suggesting a common signal transduction pathway in cell death conserved through evolution of both kingdoms. Cell Death and Differentiation (2001) 8, 776-784.
\end{abstract}

Keywords: arachidonate; calcium; membranes; mitochondrial uncoupling; peroxidation

Abbreviations: CycA, cyclosporin A; ERK, extracellular regulated kinase; ETE, eicosatetraenoic (arachidonic) acid; ETYA, eicosatetraynoic acid; FLAP, 5-lipoxygenase activating protein; GSH, reduced glutathione; $H(P)$, hydro(pero)xide; $H R$, hypersensitive response; IL-R, interleukin receptor; $\mathrm{LO}(\mathrm{O}) \mathrm{H}$, lipid hydro(pero)xide; LOX, lipoxygenase; LRP, lentil root protoplast; MAPK, mitogenactivated protein kinase; NAC, $\mathrm{N}$-acetylcysteine; NDGA, nordihydroguaiaretic acid; NF-kB, nuclear factor-kB; NSAID, nonsteroidal anti-inflammatory drug; OD, octadecadienoic (linoleic) acid; OT, octadecatrienoic (linolenic) acid; PCD, programmed cell death; nPG, n-propyl gallate; ROS, reactive oxygen species; TGF, transforming growth factor; $\mathrm{Tl}$, toxic intermediates; TNF, tumor necrosis factor

\section{The lipoxygenase family}

Lipoxygenases (linoleate:oxygen oxidoreductase, EC 1.13.11.12; LOXs) are a family of monomeric non-heme, non-sulfur iron dioxygenases, which catalyze the conversion of polyunsaturated fatty acids into conjugated hydroperoxides. The unsaturated fatty acids, which are essential in humans, are absent in most bacteria and thus LOXs are also absent in typical prokaryotes. LOXs are widely expressed in animal and plant cells, sometimes at high level, and their activity may initiate the synthesis of a signaling molecule or may induce structural or metabolic changes in the cell. Mammalian lipoxygenases have been implicated in the pathogenesis of several inflammatory conditions such as arthritis, psoriasis and bronchial asthma. ${ }^{1}$ They are also thought to have a role in atherosclerosis, brain aging, HIV infection, kidney disease and terminal differentiation of keratinocytes. In plants, lipoxygenases favor germination, participate in the synthesis of traumatin and jasmonic acid and in the response to abiotic stress. ${ }^{2}$

The phylogenetic tree shows that plant and animal LOXs are separate branches, each forming several subgroups. ${ }^{3}$ When arachidonic (eicosatetraenoic, C20:4; ETE) acid is the substrate, different LOX isozymes can add a hydroperoxy group at carbons 5,12 or 15 , and therefore they are designated 5-, 12- or 15-lipoxygenases. Linoleic (octadecadienoic, C18:2; OD) acid and linolenic (octadecatrienoic, C18:3; OT) acid are also substrates of LOXs. Soybean (Glycine max) lipoxygenase-1 (LOX-1) is a 15lipoxygenase widely used as a prototype for studying the homologous family of lipoxygenases from tissues of different species, both in structural ${ }^{4}$ and kinetic ${ }^{5}$ investigations.

The primary sequence and three dimensional structure of LOX-1 have been determined, showing that it is an ellipsoid of 90 by 65 by $60 \AA$, with 839 amino acid residues and a molecular mass of $93840 \mathrm{Da}^{3}$ LOX-1 is made of two domains: a 146-residue $\beta$-barrel at the $\mathrm{N}$-terminal (domain l) and a 693-residue helical bundle at the C-terminal (domain II). The iron-containing active site is in the center of domain II, liganded to four conserved histidines and to the carboxyl group of the C-terminal conserved isoleucine. It can be reached through the two cavities (I and II), as shown in Figure 1. Cavity I presents an ideal path for the access of molecular oxygen to iron, whereas cavity II can accommodate arachidonic acid or even slightly larger fatty acids. Mammalian lipoxygenases lack the $\mathrm{N}$-terminal domain present in LOX-1 and related plant lipoxygenases, thus showing smaller molecular mass $(75-80 \mathrm{kDa}$ compared to $94-104 \mathrm{kDa}$ in plants). The $\mathrm{N}$-terminal domain in LOX-1 makes only a loose contact with the C-terminal domain; this may be dispensable for plant lipoxygenases, 


\section{Domain I}

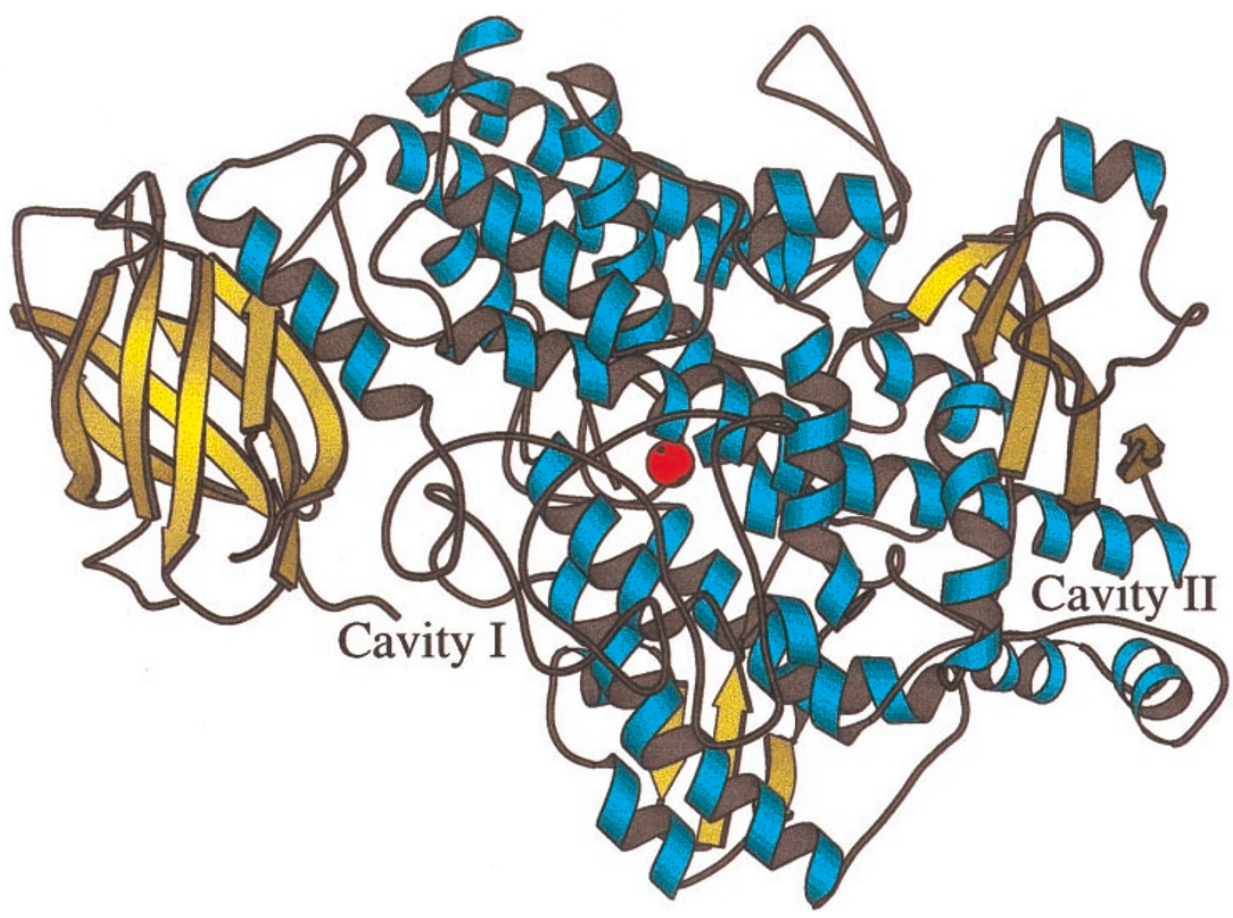

Figure 1 Schematic diagram of the three-dimensional structure of soybean (Glycine max) lipoxygenase-1, showing the small N-terminal domain I and the large Cterminal domain II. The iron-containing active site is located in domain II, and can be reached by molecular oxygen through cavity I and by arachidonic acid through cavity II. The $\beta$-sandwiches are represented in yellow, the $\alpha$-helices in blue, the random coils in gray and the iron in red. The three-dimensional structure was modeled through the MOLSCRIPT program, using the lipoxygenase-1 sequence (PDB accession number: $2 \mathrm{SBL}$ )

because all the amino acid side chains responsible for catalysis are located in the C-terminal domain. However, limited proteolysis experiments indicated that the two domains are instead tightly associated, and that domaindomain interactions play a role in the reversible unfolding of LOX-1, through ionic interactions. LOX-1 is usually in the inactive $\mathrm{Fe}^{2+}$ form and oxidation to the active $\mathrm{Fe}^{3+}$ enzyme is required for catalysis. Substrate dioxygenation by LOX-1 can be explained by two different mechanisms, indicated as 'free-radical' and 'organoiron' respectively, both compatible with the iron coordination in the active site (Figure 2A). They explain in different ways the $\mathrm{C}-\mathrm{H}$ bond cleavage of the substrate, which is the rate-limiting step of the overall dioxygenation reaction. ${ }^{3}$ The free radical mechanism assumes an involvement of $\mathrm{Fe}$ in the (stereospecific) hydrogen abstraction from the methylene group in the pentadiene system of the substrate, yielding a free radical intermediate. The hydrogen removal implies the reduction of $\mathrm{Fe}^{3+}$ to $\mathrm{Fe}^{2+}$ (Figure 2B). The organoiron hypothesis involves concerted deprotonation, catalyzed by a basic group (B) in the active site and electrophilic attack of Fe on the substrate, without any formal change in the iron oxidation state (Figure 2C).

In mammals, most work has been done on 5lipoxygenase (arachidonate:oxygen 5-oxidoreductase, EC 1.13.11.34; 5-LOX), which is found primarily in polymorphonuclear leukocytes, macrophages and mast cells, where it plays a central role in cellular leukotriene synthesis. The interaction of human 5-LOX with cellular proteins has been recently investigated through the two-hybrid approach, ${ }^{6}$ showing that this enzyme binds to proteins as different as a coactosin-like protein (an element of the cytoskeleton), a transforming growth factor (TGF) type $\beta$ receptor-Iassociated protein 1 (involved in TGF signaling), and a hypothetical helicase (a DNA metabolizing enzyme). Complex protein-protein interactions have been demonstrated in nuclear membrane translocation, activation and substrate binding by 5 -LOX in intact cells. ${ }^{3}$ In fact, cell activation by different stimuli results in translocation of 5LOX to the nuclear membrane, where it associates with a '5-LOX activating protein' (FLAP), an $18 \mathrm{kDa}$ integral membrane protein which acts as an arachidonic acid transfer protein and is essential for full leukotriene biosynthesis. FLAP shows homology with leukotriene $\mathrm{C}_{4}$ synthase and other microsomal glutathione transferases, but no enzymatic activity itself. Initially, FLAP was believed to be localized at the outer cell membrane, but later it became clear that it is associated with the nuclear envelope. Thus, arachidonic acid released from the nuclear membrane of leukocytes, and presented to 5-LOX by FLAP, may be the substrate for leukotriene synthesis. ${ }^{3}$ Recently, growing evidence has accumulated suggesting that FLAP can have effects independent of 5 -LOX. ${ }^{7}$ Also regulatory, nonenzymatic activities of 5-LOX have been 


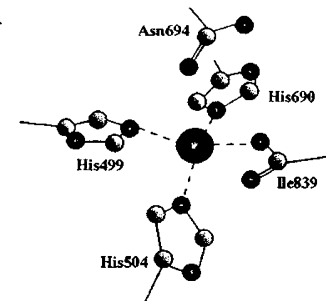

( I)



( II )
B

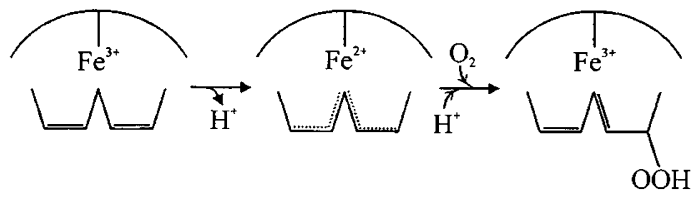

C
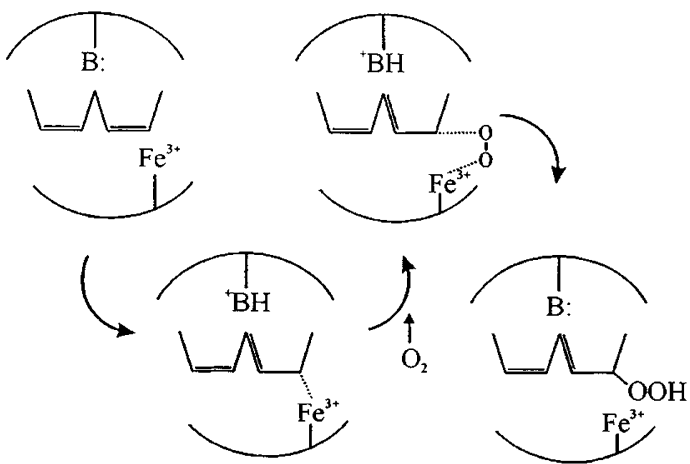

Figure 2 (A) Current views of the iron coordination in the active site of soybean (Glycine max) lipoxygenase-1: coordination by four ligands, forming a highly distorted octahedron with two unoccupied positions (I); coordination by six ligands, forming a slightly distorted octahedron (II). The free-radica model (B) and the organoiron model (C) of lipoxygenase catalysis are compatible with both views of iron coordination. See text for details reported, made possible by an Src homology 3 (SH3) binding motif, which enables the interaction with growth factor receptor-bound protein 2 (Grb2) and cytoskeletal proteins. ${ }^{6}$ In this line, a possible interaction of 5-LOX with the nuclear factor- $\kappa \mathrm{B}$ (NF- $\kappa \mathrm{B})$ complex seems to indicate that 5-LOX protein might also indirectly influence gene transcription. ${ }^{6}$ The ability of 5 -LOX to enter the nucleus supports its regulatory role on the transcription process, though possible nonenzymatic functions of 5-LOX protein wait to be investigated.

\section{Lipoxygenase involvement in apoptotic pathways}

LOX products have been shown to induce PCD in human $T$ cells, ${ }^{8}$ neutrophils, ${ }^{9} \mathrm{PC} 12 \mathrm{~h}$ cells ${ }^{10}$ and Jurkat cells. ${ }^{11}$ Therefore, it is not surprising that activation of lipoxygenases has been associated to programmed death of different cells and tissues, induced by different, unrelated stimuli (Table 1 and references therein). Several studies have shown the proapoptotic activity of 5 -LOX, ${ }^{15,23}$ of leukocyte type 12 LOX, ${ }^{21,26}$ and of $15-\mathrm{LOX}^{24,28}$ and have indicated molecular targets for lipoxygenase interaction able to contribute to the induction of apoptosis (Table 2 and references therein). However, also anti-apoptotic effects of LOXs have been reported, mainly based on the observation that LOX inhibitors, most often nordihydroguaiaretic acid (NDGA) and MK886, had pro-apoptotic activity. ${ }^{30,35,37,38}$ Interestingly, in other cellular types NDGA or MK886 protected against apoptosis, ${ }^{12-15,21,28,36}$ or induced PCD in cell types completely devoid of LOX activity. ${ }^{7,32,39}$ In this context, it should be recalled that most of the LOX inhibitors used in PCD studies, including NDGA, act by reducing the active $\mathrm{Fe}^{3+}$ enzyme to the inactive $\mathrm{Fe}^{2+}$ form (Figure 3). NDGA also blocks voltageactivated calcium currents, inhibits P450 monooxygenase activity and acts as a general radical scavenger. ${ }^{12}$ On the other hand, MK886, which inhibits 5-LOX by blocking FLAP, can also induce PCD via a caspase-3-dependent pathway

Table 1 Apoptotic pathways which upregulate lipoxygenase activity

\begin{tabular}{|c|c|c|}
\hline Stimulus & Cell type/tissue & Reference \\
\hline $\begin{array}{l}\text { TNF } \alpha \\
\text { TGF } \beta 1 \pm \text { cisplatin } \\
\text { CD95 (Fas/APO-1) ligand } \\
\text { Retinoic acid } \\
\text { Hydrogen peroxide }\end{array}$ & $\begin{array}{l}\text { Murine fibrosarcoma L929 cells } \\
\text { Human erythroleukemia K562 cells } \\
\text { Human glioma cells } \\
\text { Human neuroblastoma SK-N-BE(2) cells } \\
\text { Bean (Phaseolus vulgaris) leaves } \\
\text { Soybean (Glycine max) cells } \\
\text { Pepper (Capsicum annuum) leaves } \\
\text { Tobacco (Nicotiana tabacco) leaves } \\
\text { Human erythroleukemia K562, neuroblastoma SK-N-BE(2) } \\
\text { and melanoma B-mel cells } \\
\text { Lentil (Lens culinaris) cells }\end{array}$ & $\begin{array}{l}\text { O'Donnell et al. }{ }^{12} \\
\text { Maccarrone et al. }{ }^{13} \\
\text { Wagenknecht et al. } \\
\text { Maccarrone et al. }{ }^{14} \\
\text { Croft et al. }{ }^{16} \\
\text { Levine et al. }{ }^{17} \\
\text { Buonaurio and Servili }{ }^{18} \\
\text { Rusterucci et al. }{ }^{19} \\
\text { Maccarrone et al. }{ }^{15} \\
\text { Maccarrone et al. }{ }^{20}\end{array}$ \\
\hline Thapsigargin & Mouse MIN6 cells & Zhou et al. ${ }^{21}$ \\
\hline Bleomycin & Human lymphocytes & Vernole et $a l^{22}$ \\
\hline Tamoxifen & Human erythroleukemia K562 cells & $\begin{array}{l}\text { Maccarrone et al }{ }^{23} \\
\text { Kamitani et al.. }\end{array}$ \\
\hline Sodium butyrate & $\begin{array}{l}\text { Human colorectal carcinoma Caco- } 2 \text { cells } \\
\text { Rat intestinal epithelial cells }\end{array}$ & $\begin{array}{l}\text { Ikawa et al. }{ }^{25} \\
\text { Kamitani et al. }\end{array}$ \\
\hline $\begin{array}{l}\text { X-ray irradiation } \\
\text { NSAIDs }\end{array}$ & $\begin{array}{l}\text { Rat lymphocytes } \\
\text { Human colorectal cancer RKO and HT-29 cells }\end{array}$ & $\begin{array}{l}\text { Matyshevskaia et al. }{ }^{27} \\
\text { Shureiqi et } a l^{28}\end{array}$ \\
\hline
\end{tabular}

TNF $\alpha$, tumor necrosis factor $\alpha$; TGF $\beta 1$, transforming growth factor $\beta 1$; NSAIDs, nonsteroidal anti-inflammatory drugs 
Table 2 Reported targets for lipoxygenase interaction along different apoptotic pathways

\begin{tabular}{|c|c|c|}
\hline Molecular target & Cell type & Reference \\
\hline Membrane lipids & $\begin{array}{l}\text { Human erythroleukemia K562 cells } \\
\text { Human neuroblastoma, SK-N-BE(2) and melanoma B-mel cells } \\
\text { Human HL-60 cells } \\
\text { Human leukemia WSU cells }\end{array}$ & $\begin{array}{l}\text { Maccarrone et al. }{ }^{13,15,23} \\
\text { Maccarrone et al. } \\
\text { Surette et al. }{ }^{29} \\
\text { Datta et al. }\end{array}$ \\
\hline Phospholipase $\mathrm{A}_{2}$ & Rat carcinosarcoma W256 cells & Tang et al. ${ }^{30}$ \\
\hline Phospholipase C & Human carcinoma A431 cells & Szekeres et al. ${ }^{31}$ \\
\hline Mitochondria & $\begin{array}{l}\text { Murine hematopoietic FL5.12 cells } \\
\text { Human erythroleukemia K562 and neuroblastoma CHP100 cells }\end{array}$ & $\begin{array}{l}\text { Biswal et al. } \\
\text { Maccarrone et al. }\end{array}$ \\
\hline Free radicals & $\begin{array}{l}\text { Human erythroleukemia K562, neuroblastoma SK-N-BE(2) and } \\
\text { melanoma B-mel cells } \\
\text { Human vascular smooth muscle cells } \\
\text { Human leukemia WSU cells }\end{array}$ & $\begin{array}{l}\text { Maccarrone et al. }{ }^{15} \\
\text { Metzler et al. }{ }^{34} \\
\text { Datta et } \text { al. }^{7}\end{array}$ \\
\hline Calcium stores & $\begin{array}{l}\text { Human lymphoma U937 cells } \\
\text { Mouse MIN6 cells } \\
\text { Human erythroleukemia K562 and neuroblastoma CHP100 cells }\end{array}$ & $\begin{array}{l}\text { Buyn et al. } \\
\text { Zhou et al. } \\
\text { Maccarrone et al. }\end{array}$ \\
\hline Caspases & Human glioma cells & Wagenknecht et al. ${ }^{14}$ \\
\hline MAPK phosphatase-1 & Human vascular smooth muscle cells & Metzler et al. ${ }^{34}$ \\
\hline P38-MAPK & Human lung fibroblasts & Aoshiba et al. ${ }^{36}$ \\
\hline Protein kinase $\mathrm{C}$ & Human carcinoma A431 cells & Szekeres et al. ${ }^{31}$ \\
\hline ERK $1 / 2$ & Human carcinoma A431 cells & Szekeres et al. ${ }^{31}$ \\
\hline Ras & $\begin{array}{l}\text { Human erythroleukemia K562 cells } \\
\text { Human carcinoma A431 cells }\end{array}$ & $\begin{array}{l}\text { Maccarrone et al }{ }^{23} \\
\text { Szekeres et al. }\end{array}$ \\
\hline
\end{tabular}

MAPK, mitogen-activated protein kinase; ERK, extracellular regulated kinase

nordihyd roguaiaretic acid (NDGA)<smiles>CC(Cc1ccc(O)c(O)c1)C(C)Cc1ccc(O)c(O)c1</smiles>

MK886<smiles>CC(C)c1ccc2c(c1)-c1c-2c(SC(C)(C)C)n(Cc2ccc(Cl)cc2)c1CC(C)(C)C(=O)O</smiles><smiles>Cc1c(C)c2c(c(C)c1O)CCC(C)(CCCC(C)CCCC(C)CCCC(C)C)O2</smiles>

Figure 3 Inhibitors of lipoxygenase activity widely used in investigations on programmed cell death. These compounds reduce the active $\mathrm{Fe}^{3+}$ enzyme to the inactive $\mathrm{Fe}^{2+}$ form, apart from MK886 which inhibits the 5-lipoxygenase activating protein (FLAP)

which is related to bcl- $x_{\mathrm{L}}$ but unrelated to 5 -LOX. ${ }^{7}$ Recently, MK886 has been found to be effective as PCD inducer at doses 100-fold higher than those required for 5-LOX inhibition, in a human cell line which lacks FLAP and its mRNA. ${ }^{7}$ Resveratrol, an alleged natural cancer preventive agent present in red wine, ${ }^{40}$ has been shown to inhibit PCD induced by unrelated stimuli in human erythroleukemia K562 cells, through competitive inhibition of 5-LOX and 15-LOX activity. ${ }^{41}$ However, resveratrol is a general antioxidant which also inhibits nonenzymatic lipoperoxidation and cyclooxygenase activity ${ }^{41}$ and acts as an agonist for the estrogen receptor. ${ }^{42}$ Finally caffeic acid, which prevents apoptosis linked to 5-LOX activation, ${ }^{15}$ is a LOX inhibitor with general antioxidant properties, ${ }^{43}$ much like the 5-LOX inhibitor $\alpha$ tocopherol. ${ }^{44}$ In a recent investigation, we sought to overcome the problem of the specificity of LOX inhibitors, by treating human cells with physiological concentrations of the hydroperoxide products generated by the main mammalian lipoxygenase isozymes: 5-, 12- and 15-hydroperoxyeicosatetraenoic acids (5-, 12- and 15-HPETE), 13-hydroperoxyoctadecadienoic acid (13-HPOD) and 13-hydroperoxyoctadecatrienoic acid (13-HPOT). The structure of these hydroperoxides is shown in Figure 4. We demonstrated that all these hydroperoxy fatty acids are fully capable of eliciting apoptotic bodies formation, both in human erythroleukemia and neuroblastoma cells. ${ }^{13}$ The most active compound is that generated by 5-lipoxygenase from arachidonate (5-HPETE), followed by 13-HPOT, 15-HPETE, 9-HPOT, 9-HPOD, 13HPOD and 12-HPETE. In this context, it should be recalled that mammalian cells can reduce the lipid hydroperoxides $(\mathrm{LOOH})$ to the purportedly less toxic hydroxides ( $\mathrm{LOH}$ ), in a reaction requiring glutathione $(\mathrm{GSH})$ and catalyzed by glutathione peroxidase: ${ }^{45}$

$$
\mathrm{LOOH}+2 \mathrm{GSH} \rightarrow \mathrm{LOH}+\mathrm{GSSG}+\mathrm{H}_{2} \mathrm{O}
$$

Therefore, depletion of intracellular GSH might enhance hydroperoxide-induced PCD, by analogy with other apoptotic pathways such as that induced by Fas. However, we found that apoptosis induced by LOX 

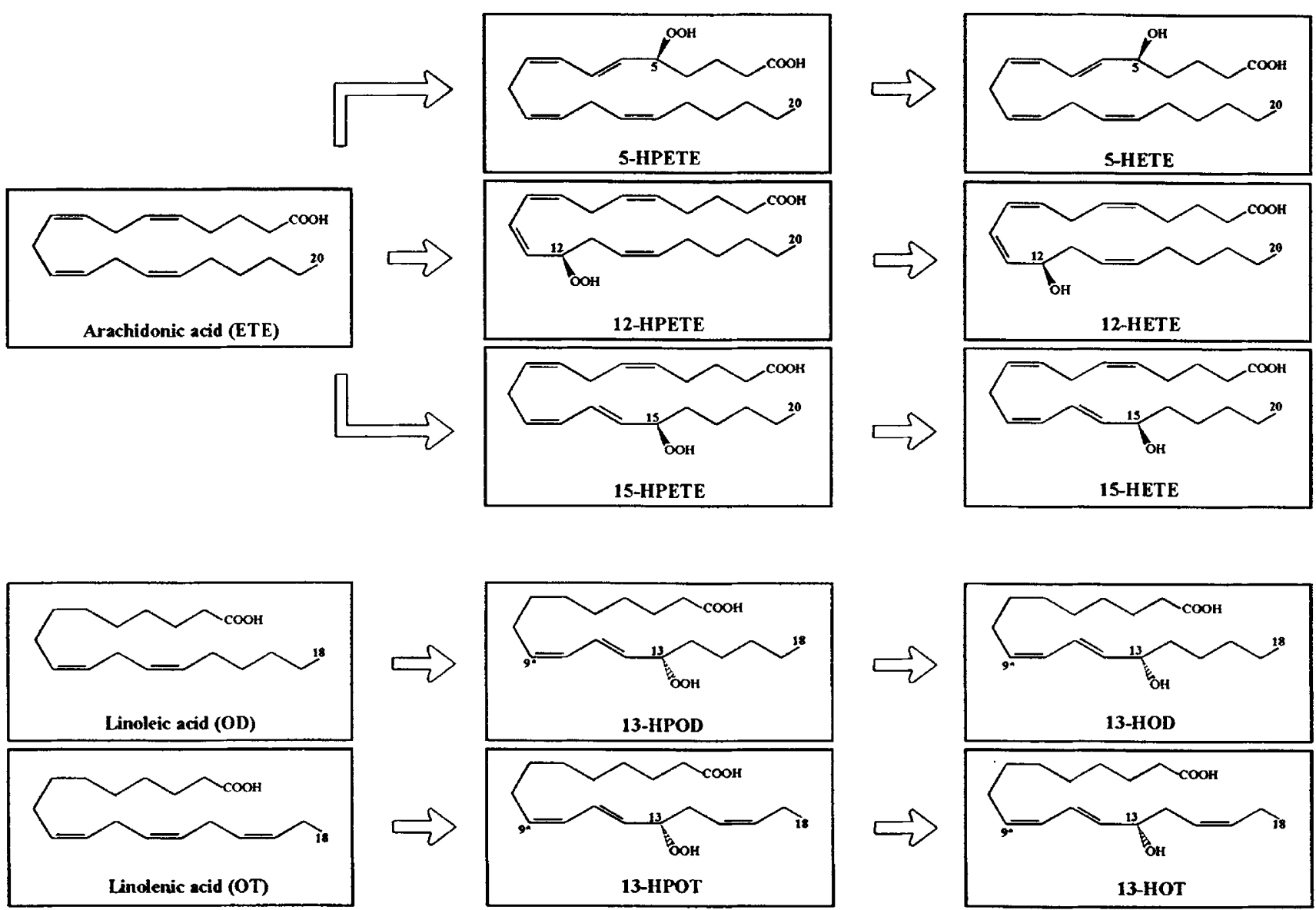

Figure 4 Hydroperoxides generated by different lipoxygenases (LOXs) with arachidonic, linoleic or linolenic acids as substrates. The hydroperoxides can be reduced to the corresponding hydroxides by cellular glutathione peroxidases, which concomitantly convert reduced glutathione (GSH) to its oxidized form (GSSG). Asterisks mark the hydro(pero)xide position in 9-H(P)OD and 9-H(P)OT

products was independent of intracellular GSH, and that the hydroxides derived by reduction of the LOX hydroperoxy products were as effective in inducing PCD as the corresponding peroxides. These findings are at variance with previous reports that some lipoxygenase products (namely, 12- and 15-HETEs, but not their metabolic precursors 12- and 15-HPETEs) may protect cells, whereas others (namely, 5-HETE) are toxic. ${ }^{30,38}$ Unlike the hydro(pero)xides, the terminal products of the LOX pathway (leukotrienes) are not cytotoxic. ${ }^{33}$ Moreover, neither RNA nor protein synthesis appear to have a role in lipid hydro(pero)xide-induced PCD, which instead is paralleled by an increase (within seconds) in intracellular calcium, ${ }^{33}$ extending previous observations on unrelated models of PCD. ${ }^{21,35,46}$ The mechanism of the hydroperoxide-induced calcium increase is not due to an increase in permeability of the plasma membrane, since calcium was absent in the extracellular medium. Most probably, the hydro(pero)xides may stimulate the release of calcium from mitochondrial and endoplasmic stores. ${ }^{8}$ This hypothesis is in agreement with the observation that they are also able to uncouple mitochondria within hours. ${ }^{33}$ It is noteworthy that 15-LOX activity can dioxygenate mitochondrial membranes, leading to formation of pore-like structures observable by electron microscopy also in membranes of endoplasmic reticulum, thus initiating programmed organelle disruption. ${ }^{47}$ On the other hand, the role of mitochondria as key players in death programmes is well established, ${ }^{48}$ yet the mechanisms responsible for the release of mitochondrial components which affect apoptosis remain obscure. ${ }^{49}$

Here, we sought to assess whether lipoxygenase activity might cause mitochondrial damage associated to apoptosis. We isolated mitochondria from human erythroleukemia K562 cells, and studied the effect induced by LOXs on: (i) the oxidative index of membranes, a marker of lipoperoxidation; (ii) the dissipation of mitochondrial membrane potential; and (iii) the release of cytochrome $c$, using specific anti-cytochrome $c$ monoclonal antibodies in the 
enzyme-linked immunosorbent assays. ${ }^{50}$ Mitochondria were treated with pure soybean lipoxygenase-1, which is a 15LOX widely used as a prototype for studying the structural and kinetic properties of mammalian lipoxygenases. ${ }^{3-5}$

We found that treatment of mitochondrial suspensions with amounts of soybean 15-LOX within the physiological range, ${ }^{47}$ dose-dependently increased the oxidative index (up to threefold over the control) and the uncoupling of mitochondria (up to eightfold over the control), both indicative of the disruption of membrane integrity (Figure $5 A$ ). Remarkably, incubation of mitochondria with 15-LOX caused also a dose-dependent release of cytochrome $c$ (up to fivefold over the control), a critical trigger of apoptosis induced by several unrelated stimuli. ${ }^{51}$ The lipoxygenase inhibitors eicosatetraynoic acid (ETYA) and n-propyl gallate (nPG) fully prevented these effects of 15-LOX (Figure 5A), corroborating the previous observation that they block 15LOX-dependent formation of pore-like structures in endoplasmic reticulum membranes. ${ }^{47}$ On the other hand, cyclosporin $\mathrm{A}$, a mitochondrial permeability transition pore inhibitor, ${ }^{49}$ was ineffective (Figure $5 \mathrm{~A}$ ), suggesting that opening of this type of pores did not contribute to mitochondrial membrane disruption by 15-LOX. We extended the study to the other available LOX isozymes, incubating mitochondrial suspensions under the same experimental conditions as those used with soybean 15LOX. We found that rabbit reticulocyte 15-LOX was more effective than the soybean enzyme, whereas barley (Hordeum vulgare) 5-LOX was as effective and human platelet 12-LOX was less effective than soybean 15-LOX (Figure 5B).

Taken together, the present results suggest that lipoxygenases, in the order 15-LOX $>5$-LOX $>12$-LOX, are able to disrupt mitochondrial integrity and to trigger cytochrome $c$ release, thus giving a biochemical ground to the observation that activation of these enzymes is critical in different models of apoptosis (Table 1). It can be suggested that LOXs, by introducing molecular oxygen into the fatty acid moieties of (phospho)lipids and thus increasing membrane lipoperoxidation (Figure 5), can alter fluidity and permeability of biomembranes. These modifications might be the basis for the formation of pore-like structures in membranes, ${ }^{47}$ which cause dissipation of the mitochondrial potential and favor cytochrome $c$ release (Figure 5). Remarkably, this LOX-mediated disruption of mitochondrial integrity represents a controlled mechanism, which might allow the 'delicate' (i.e., without severe damage of structure and function) release of cytochrome $c$ observed in various models of apoptosis. ${ }^{51}$ In conclusion, we suggest that activation of LOXs might be a means to disrupt the integrity of mitochondria and to allow the release of pro-apoptotic proteins from these organelles. Further work should be aimed at ascertaining whether the effects of LOX on mitochondria can be inhibited by $\mathrm{Bcl}-2$ family members. ${ }^{52}$ This information would be of great value for understanding more general aspects of the release of apoptotic factors from mitochondria and, for example, the relationship with the permeability transition. In this line, it may be worth reminding that lipoxygenase activation has been shown to affect also cytoskeleton organization and


Lipoxygenase isozyme (50 units/test)

Figure 5 (A) Dose-dependence of different mitochondrial parameters on the amount of soybean 15-lipoxygenase (15-LOX). Suspensions of mitochondria $(200 \mu \mathrm{l} /$ test $)$ were incubated for $3 \mathrm{~h}$ at $25^{\circ} \mathrm{C}$, and controls were treated with incubation buffer alone ( $140 \mathrm{mM} \mathrm{NaCl}, 5 \mathrm{mM} \mathrm{KCl}, 1 \mathrm{mM} \mathrm{MgCl}_{2}, 1.8 \mathrm{mM} \mathrm{CaCl}_{2}$ $10 \mathrm{mM}$ glucose, $0.1 \%$ bovine serum albumin, $15 \mathrm{mM}$ HEPES, $\mathrm{pH} 7.4$ ). Lipoxygenase inhibitors eicosatetraynoic acid (EYTA, $10 \mu \mathrm{M}$ ) and n-propyl gallate (nPG, $100 \mu \mathrm{M})$, and permeability transition pore inhibitor cyclosporin $A$ (CycA, $10 \mu \mathrm{M})$, were added to the mitochondrial suspensions at the same time as 15-LOX. All increases induced by 15-LOX were significant vs controls: $P<0.05$ for oxidative index and cytochrome $c$ release at 25 units/test, $P<0.01$ in all other cases. ${ }^{*} P<0.01,{ }^{* *} P>0.05$ vs samples treated with 15 -LOX (100 units/test). (B) Effect of different LOX isozymes on the same mitochondrial parameters as those shown in $\mathbf{A}$. ${ }^{\star} P<0.05$ vs controls; in all other cases, $P$ values vs controls were $<0.01$. Results are shown as mean \pm S.D. of four independent experiments, each performed in duplicate

protein phosphorylation, ${ }^{6}$ which can be instrumental in promoting PCD. In fact, we have previously shown that LOX activation is an early event along different apoptotic pathways, and occurs several hours before any typical sign of apoptosis at nuclear level. ${ }^{15,53}$ Furthermore, early LOX 
activation was not observed in necrotic cells, ${ }^{53}$ thus representing the first biochemical difference between the initiation of apoptosis and that of necrosis so far described.

Overall, physical (UV-light) or chemical (drugs, oxidative stress, serum starvation) induction of PCD, as well as apoptotic pathways mediated by receptors such as CD28, interleukin receptor or Fas, have been shown to involve LOX activation, which in turn is accompanied by modifications of: (i) membrane properties (lipoperoxidation, exposure of phosphatidylserine, increased levels of cholesterol and consequent altered Ras expression, generation of free hydroperoxides); (ii) cytoskeleton (at the level of coactosinlike protein, lamins, Gas 2 and $\alpha$-fodrin), and (iii) gene transcription (through NF- $\kappa \mathrm{B}$, poly(ADP-ribose) polymerase and reactive oxygen species). We could therefore hypothesize a model of 'Redox Stress Sensor', depicted in Figure 6. LOX activity generates toxic intermediates (such as hydroperoxides and superoxide anions), which lead to apoptosis by increasing membrane fluidity and permeability, intracellular calcium concentration, mitochondrial uncoupling and cytochrome $c$ release. The intracellular level of glutathione, regulated by $\mathrm{N}$-acetylcysteine, counteracts the effect of LOX activity, also by possibly promoting detoxification of its intermediates. The equilibrium between LOX and glutathione might interfere with the intracellular level of reactive oxygen species. Collectively, the balance between these elements, and the status of the membranes, will finely tune the sensitivity of the cell to resist to redox stresses or to die.

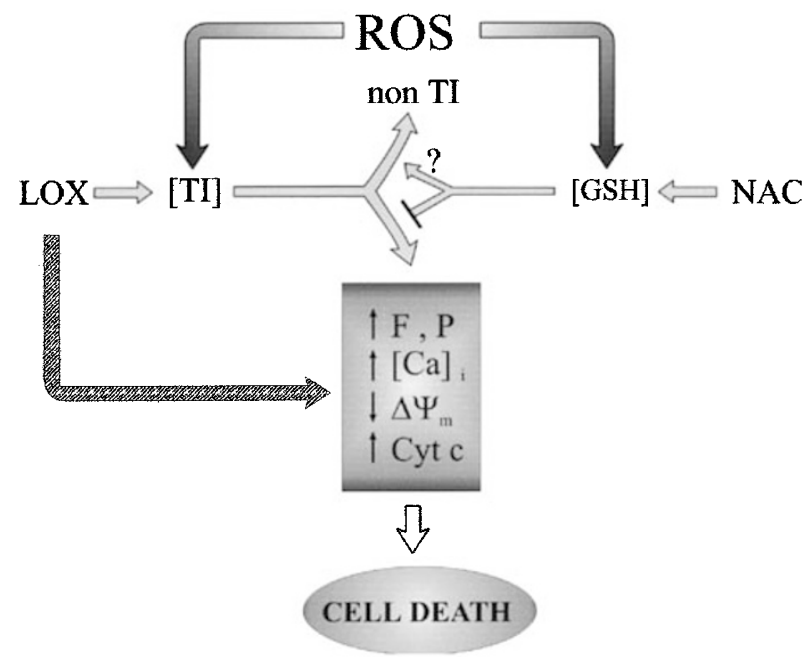

Figure 6 The 'Redox Stress Sensor' model, whereby lipoxygenase (LOX) activity generates toxic intermediates (TI), which lead to apoptosis by (i) increasing membrane fluidity $(F)$ and permeability $(P)$, (ii) elevating intracellular calcium concentration $\left([\mathrm{Ca}]_{\mathrm{i}}\right)$, (iii) decreasing mitochondrial membrane potential $(\Delta \Psi \mathrm{m})$, and (iv) increasing cytochrome $c$ (Cyt $c$ ) release. The intracellular level of glutathione $(\mathrm{GSH})$, regulated by $N$ acetylcysteine (NAC), counteracts the effect of LOX activity, also by possibly promoting detoxification of $\mathrm{TI}$ to non-toxic species. The equilibrium between LOX and GSH might interfere with the intracellular level of reactive oxygen species (ROS). This picture is further complicated by the ability of LOX to induce directly the events triggered by the toxic intermediates

\section{Plant lipoxygenases and apoptosis}

In plants, PCD has been associated to various phases of development and senescence, germination, and response to cold or salt stress. ${ }^{54}$ A type of PCD of particular interest has been observed during the plant response to pathogen attack, that was termed 'hypersensitive response (HR)'. 17,54 Signal transduction pathways are activated during HR, leading to biosynthesis or release of potential antimicrobial effector molecules, which are thought to contribute to both host and pathogen cell death. ${ }^{54}$ Among other signals, rapid generation of reactive oxygen species has been implicated in HR of plants against pathogens. ${ }^{17}$ In particular, hydrogen peroxide has been shown to be a crucial component of the HR control circuit, since a short pulse of exogenous $\mathrm{H}_{2} \mathrm{O}_{2}$ is sufficient to activate the hypersensitive cell death program in soybean cells. ${ }^{17}$ A similar HR has been observed also in bean, ${ }^{16}$ pepper $^{18}$ and tobacco ${ }^{19}$ leaves, infected with different pathogens. Interestingly, LOX activation has been associated to $\mathrm{HR},{ }^{18,19}$ and $\mathrm{H}_{2} \mathrm{O}_{2}$ oxidative stress has been shown to induce animal cell apoptosis, through activation of 5-LOX. ${ }^{15}$

Recently, we have used oxidative stress by exogenous $\mathrm{H}_{2} \mathrm{O}_{2}$ to investigate whether LOX activation was a cause rather than an effect of plant cell apoptosis. Lentil (Lens culinaris) lipoxygenase has been characterized, cloned and expressed in Escherichia coli, ${ }^{55}$ therefore lentil root protoplasts (LRP) were chosen as a model. It was shown that the early phase of hydrogen peroxide-induced apoptosis is characterized by enhancement of lipoxygenase activity, attributable to up-regulation of gene expression at both transcriptional and translational level. The increase of lipoxygenase was paralleled by an enhancement of ultraweak luminescence, a marker of LOX-related membrane lipid peroxidation. ${ }^{20}$ These findings suggest that lipoxygenase activation might contribute to membrane peroxidation during hydrogen peroxide-induced CPD, resembling previous observations on animal cells. ${ }^{15}$ NDGA protected LRP against $\mathrm{H}_{2} \mathrm{O}_{2}$-induced DNA fragmentation and ultraweak luminescence. However, in view of the lack of specificity of this LOX inhibitor, we also used inhibitory anti-LOX monoclonal antibodies, able to block LOX activity in LRP without affecting the redox state of the cell. ${ }^{20}$ These antibodies, too, protected LRP against $\mathrm{H}_{2} \mathrm{O}_{2}$-induced PCD, whilst the specific products of LRP lipoxygenase, 9-HPOD and 13-HPOD, were able per se to induce DNA fragmentation. ${ }^{20}$ Also $9-\mathrm{HOD}$ and $13-\mathrm{HOD}$, the reduced forms of the LRP LOX products, were able to induce cell death and DNA fragmentation to almost the same extent as the corresponding HPODs, again matching previous observations on human cells. ${ }^{20}$ Since similar findings were reported in $\mathrm{H}_{2} \mathrm{O}_{2}$-induced $P C D$ of human cells, these observations suggest that animals and plants share a common signal transduction pathway triggering apoptosis after oxidative stress.

\section{Conclusions}

Activation of different LOX isozymes has been shown to be associated to an early phase of apoptosis, triggered by several, unrelated stimuli. Consistently, LOXs and the 
hydro(pero)xides generated by their activity have been shown to induce programmed cell death in different cellular models, through a series of events including an immediate and sustained rise in cytosolic calcium (within seconds), followed by mitochondrial uncoupling and cytochrome $c$ release (within hours). Animal and plant cells share a similar signal transduction pathway able to trigger apoptosis after oxidative stress, based on lipoxygenase activation.

\section{Acknowledgements}

We thank Dr. Mattia Falconi for the molecular model of LOX-1 and Mr. Graziano Bonelli for the excellent production of the artwork. All colleagues at University of Rome Tor Vergata and at Utrecht University who took part over the years in the study of the role of lipoxygenases in programmed cell death are gratefully acknowledged as well. This work was supported by Istituto Superiore di Sanità, Rome, through a III Aids Project grant (to $\mathrm{A}$ Finazzi-Agrò), and by EU grant QL661-1999-00739, Telethon E872, AIRC and MURST-Cofin (to G Melino).

\section{References}

1. Kühn H and Borngraber S (1999) Mammalian 15-lipoxygenases. Enzymatic properties and biological implications. Adv. Exp. Med. Biol. 447: 5-28

2. Grechkin A (1998) Recent developments in biochemistry of the plant lipoxygenase pathway. Prog. Lipid. Res. 37: 317-352

3. Brash AR (1999) Lipoxygenases: occurrence, functions, catalysis, and acquisition of substrate. J. Biol. Chem. 274: 23679-23682

4. Sudharshan E and Appu Rao AG (1999) Involvement of cysteine residues and domain interactions in the reversible unfolding of lipoxygenase-1. J. Biol. Chem. 274: $35351-35358$

5. Clapp CH, McKown J, Xu H, Grandizio AM, Yang G and FayerJ (2000) The action of soybean lipoxygenase-1 on 12-iodo-cis-9-octadecenoic acid: the importance of C11- $\mathrm{H}$ bond breaking. Biochemistry 39: 2603-2611

6. Provost P, Samuelsson B and Radmark O (1999) Interaction of 5-lipoxygenase with cellular proteins. Proc. Natl. Acad. Sci. USA 96: 1881-1885

7. Datta K, Biswal SS and Kehrer JP (1999) The 5-lipoxygenase-activating protein (FLAP) inhibitor, MK886, induces apoptosis independently of FLAP. Biochem. J. 340: $371-375$

8. Sandstrom PA, Pardi D, Tebbey PW, Dudek RW, Terrian DM, Folks TM and Buttke TM (1995) Lipid hydroperoxide-induced apoptosis: lack of inhibition by Bcl-2 over-expression. FEBS Lett. 365: 66-70

9. Hébert M-J, Takano T, Holthöfer Hand Brady HR (1996) Sequential morphologic events during apoptosis of human neutrophils. Modulation by lipoxygenasederived eicosanoids. J. Immunol. 157: 3105-3115

10. Aoshima H, Satoh T, Sakai N, Yamada M, Enokido Y, Ikeuchi T and Hatanaka $H$ (1997) Generation of free radicals during lipid hydroperoxide-triggered apoptosis in PC12h cells. Biochim. Biophys. Acta 1345: 35-42

11. Liberles SD and Schreiber SL (2000) Apoptosis-inducing natural products found in utero during murine pregnancy. Chem. Biol. 7: 365-372

12. O'Donnell VB, Spycher S and Azzi A (1995) Involvement of oxidants and oxidantgenerating enzyme(s) in tumour-necrosis-factor- $\alpha$-mediated apoptosis: role for lipoxygenase pathway but not mitochondrial respiratory chain. Biochem. J. 310: $133-141$

13. Maccarrone M, Nieuwenhuizen WF, Dullens HFJ, Catani MV, Melino G, Veldink GA, Vliegenthart JFG and Finazzi-Agrò A (1996) Membrane modifications in human erythroleukemia $\mathrm{K} 562$ cells during induction of programmed cell death by transforming growth factor $\beta 1$ or cisplatin. Eur. J. Biochem. 241: 297-302

14. Wagenknecht B, Schulz JB, Gulbins E and Weller M (1998) Crm-A, bcl-2 and NDGA inhibit CD95L-induced apoptosis of malignant glioma cells at the level of caspase 8 processing. Cell Death Differ. 5: 894-900
15. Maccarrone M, Catani MV, Finazzi-Agrò A and Melino G (1997) Involvement of 5lipoxygenase in programmed cell death of cancer cells. Cell Death Differ. 4: 396- 402

16. Croft KPC, Voisey CR and Slusarenko AJ (1990) Mechanism of hypersensitive cell collapse: correlation of increased lipoxygenase with membrane damage in leaves of Phaseolus vulgaris (L.) cv. Red Mexican inoculated with avirulent race 1 of Pseudomonas syringae pv. phaseolicola. Physiol. Mol. Plant Pathol. 36: $49-62$

17. Levine A, Tenhaken R, Dixon Rand LambC (1994) $\mathrm{H}_{2} \mathrm{O}_{2}$ from the oxidative burs orchestrates the plant hypersensitive disease resistance response. Cell 79: $583-593$

18. Buonaurio R and Servili M (1999) Involvement of lipoxygenase, lipoxygenase pathway volatiles, and lipid peroxidation during the hypersensitive reaction of pepper leaves to Xanthomonas campestris pv. vesicatoria. Physiol. Mol. Plant Pathol. 54: 155-169

19. Rusterucci C, Montillet JL, Agnel JP, Battesti C, Alonso B, Knoll A, Bessoule JJ, Etienne P, Suty L, Blein JP and Triantaphylides C (1999) Involvement of lipoxygenase-dependent production of fatty acid hydroperoxides in the development of the hypersensitive cell death induced by cryptogein on tobacco leaves. J. Biol. Chem. 274: 36446-36455

20. Maccarrone M, Van Zadelhoff G, Veldink GA, VliegenthartJFG and Finazzi-Agrò A (2000) Early activation of lipoxygenase in lentil (Lens culinaris) root protoplasts by oxidative stress induces programmed cell death. Eur. J. Biochem. 267:50785084

21. Zhou YP, Teng D, Dralyuk F, Ostrega D, Roe MW, Philipson L and Polonsky KS (1998) Apoptosis in insulin-secreting cells. Evidence for the role of intracellular Ca2+ stores and arachidonic acid metabolism. J. Clin. Invest. 101: 1623-1632

22. Vernole $P$, Tedeschi B, Caporossi D, Maccarrone M, Melino G and Annicchiarico-Petruzzelli M (1998) Induction of apoptosis by bleomycin in resting and cycling human lymphocytes. Mutagenesis 13: 209-215

23. Maccarrone M, Fantini C, Ranalli M, Melino G and Finazzi-Agrò A (1998) Activation of nitric oxide synthase is involved in tamoxifen-induced apoptosis of human erythroleukemia K562 cells. FEBS Lett. 434: 421-424

24. Kamitani H, Geller M and Eling T (1998) Expression of 15-lipoxygenase by human colorectal carcinoma Caco-2 cells during apoptosis and cell differentiation. J. Biol. Chem. 273: 21569-21577

25. Ikawa H, Kamitani H, Calvo BF, Foley JF and Eling TE (1999) Expression of 15lipoxygenase-1 in human colorectal cancer. Cancer Res. 59: 360-366

26. Kamitani H, lkawa H, Hsi LC, Watanabe T, DuBois RN and Eling TE (1999) Regulation of 12-lipoxygenase in rat intestinal epithelial cells during differentiation and apoptosis induced by sodium butyrate. Arch. Biochem. Biophys. 368: 45-55

27. Matyshevskaia OP, Pastukh VN and Solodushko VA (1999) Inhibition of lipoxygenase activity reduces radiation-induced DNA fragmentation in lymphocytes. Radiat. Biol. Radioecol. 39: 282-286

28. Shureiqi I, Chen D, Lee JJ, Yang P, Newman RA, Brenner DE, Lotan R, Fischer SM and Lippman SM (2000) 15-LOX-1: a novel molecular target of nonsteroidal anti-inflammatory drug-induced apoptosis in colorectal cancer cells. J. Natl. Cancer Inst. 92: $1136-1142$

29. Surette ME, Fonteh AN, Bernatchez C and Chilton FH (1999) Perturbations in the control of cellular arachidonic acid levels block cell growth and induce apoptosis in HL-60 cells. Carcinogenesis 20: 757-763

30. Tang DG, Guan K-L, Li L, Honn KV, Chen YQ, Rice RL, Taylor JD and Porter AT (1997) Suppression of W256 carcinosarcoma cell apoptosis by arachidonic acid and other polyunsaturated fatty acids. Int. J. Cancer 72: 1078-1087

31. Szekeres CK, Tang K, Trikha M and Honn KV (2000) Eicosanoid activation of extracellular signal-regulated kinase $1 / 2$ in human epidermoid carcinoma cells. J. Biol. Chem. 275: 38831-38841

32. Biswal SS, Datta K, Shaw SD, Feng X, Robertson JD and Kehrer JP (2000) Glutathione oxidation and mitochondrial depolarization as mechanisms of nordihydroguaiaretic acid-induced apoptosis in lipoxygenase-deficient FL5.12 cells. Toxicol. Sci. 53: $77-83$

33. Maccarrone M, Ranalli M, Bellincampi L, Salucci ML, Sabatini S, Melino G and Finazzi-Agrò A (2000) Activation of different lipoxygenase isozymes induces apoptosis in human erythroleukemia and neuroblastoma cells. Biochem. Biophys. Res. Commun. 272: 345-350 
34. MetzlerB, HuY, Sturm G, Wick GandXu Q (1998) Induction of mitogen-activated protein kinase phosphatase-1 by arachidonic acid in vascular smooth muscle cells. J. Biol. Chem. 273: 33320-33326

35. Buyn T, Dudeja P, Harris JE, Ou D, Seed T, Sawlani D, Meng J, Bonomi P and Anderson KM (1997) A 5-lipoxygenase inhibitor at micromolar concentration raises intracellular calcium in U937 cells prior to their physiologic cell death. Prostaglandins Leukot. Essent. Fatty Acids 56: 67-77

36. Aoshiba K, Yasui S, Nishimura K and Nagai A (1999) Thiol depletion induces apoptosis in cultured lung fibroblasts. Am. J. Respir. Cell. Mol. Biol. 21: 54-64

37. Ghosh J and Myers CE (1998) Inhibition of arachidonate 5-lipoxygenase triggers massive apoptosis in human prostate cancercells. Proc. Natl. Acad. Sci. USA 95: $13182-13187$

38. Tang K, Nie D and Honn KV (1999) Role of autocrine motility factor in a 12lipoxygenase dependent anti-apoptotic pathway. Adv. Exp. Med. Biol. 469: 583-590

39. Vanags DM, Larsson P, Feltenmark S, Jakobsson P-J, Orrenius S, Claesson H-E and Aguilar-Santelises M (1997) Inhibitors of arachidonic acid metabolism reduce DNA and nuclear fragmentation induced by TNF plus cycloheximide in U937 cells. Cell Death Differ. 4: 479-486

40. Jang M, Cai L, Udeani GO, Slowing KV, Thomas CF, Beecher CWW, Fong HHS Farnsworth NR, Kinghorn AD, Metha RG, Moon RC and Pezzuto JM (1997) Cancer chemopreventive activity of resveratrol, a natural product derived from grapes. Science 275: $218-220$

41. Maccarrone M, Lorenzon T, Guerrieri P and Finazzi-Agrò A (1999) Resveratrol prevents apoptosis in K562 cells by inhibiting lipoxygenase and cyclooxygenase activity. Eur. J. Biochem. 265: 27-34

42. Gehm BD, McAndrews JM, Chien PY and Jameson JL (1997) Resveratrol, a polyphenolic compound found in grapes and wine, is an agonist for the estrogen receptor. Proc. Natl. Acad. Sci. USA 94: 14138-14143

43. Sud'ina GF, Mirzoeva OK, Pushkareva MA, Korshunova GA, Sumbatyan NV and Varfolomeev SD (1993) Caffeic acid phenethyl ester as a lipoxygenase inhibitor with antioxidant properties. FEBS Lett. 329: 21-24

44. Maccarrone M, Taccone-Gallucci M, Meloni C, Cococcetta N, Manca di Villahermosa S, Casciani U and Finazzi-Agrò A (1999) Activation of 5lipoxygenase and related cell membrane lipoperoxidation in hemodialysis patients. J. Am. Soc. Nephrol. 10: 1991-1996
45. Schnurr K, Belkner J, Ursini F, Schewe T and Kuhn H (1996) The selenoenzyme phospholipid hydroperoxide glutathione peroxidase controls the activity of the 15-lipoxygenase with complex substrates and preserves the specificity of the oxygenation products. J. Biol. Chem. 271: 4653-4658

46. Fadok VA, Xue D and Henson $P$ (2001) If phosphatidylserine is the death knell, a new phosphatidylserine-specific receptor is the bellringer. Cell Death Differ. 8: $582-587$

47. Van Leyen K, Duvoisin RM, Engelhardt $H$ and Wiedmann M (1998) A function for lipoxygenase in programmed organelle degradation. Nature 395: 392-395

48. Vieira HLA, Haouzi D, El Hamel El, Jacotot E, Belzacq A-S, Brenner C and Kroemer $G$ (2000) Permeabilization of the mitochondrial inner membrane during apoptosis: impact of the adenine nucleotide translocator. Cell Death Differ. 7: 1146-1154

49. Bernardi P, Petronilli V, Di Lisa F and Forte M (2001)A mitochondrial perspective on cell death. Trends Biochem. Sci. 26: 112-117

50. Maccarrone M, Lorenzon T, Bari M, Melino G and Finazzi-Agrò A (2000) Anandamide induces apoptosis in human cells via vanilloid receptors. Evidence for a protective role of cannabinoid receptors. J. Biol. Chem. 275: 31938-31945

51. Von Ahsen O, Waterhouse NJ, Kuwana T, Newmeyer DD and Green DR (2000) The 'harmless' release of cytochrome c. Cell Death Differ. 7: 1192-1199

52. Roucou X and Martinou J-C (2001) Conformational change of Bax: a question of life or death. Cell Death Differ. 8: in press

53. Maccarrone M, Salucci ML, Melino G, Rosato N and Finazzi-Agrò A (1999) The early phase of apoptosis in human neuroblastoma CHP100 cells is characterized by lipoxygenase-dependent ultraweak light emission. Biochem. Biophys. Res. Commun. 265: 758-762

54. Morel J-B and Dangl JL (1997) The hypersensitive response and the induction of cell death in plants. Cell Death Differ. 4: 671-683

55. Hilbers MP, Finazzi-Agrò A, Veldink GA and VliegenthartJFG(1996) Purification and characterization of a lentil seedling lipoxygenase expressed in E. coli. Int. J. Biochem. Cell Biol. 28: $751-760$ 